\title{
Mulheres e jogos eletrônicos: muitas jogadoras, poucas programadoras!
}

\author{
Carla Denise Castanho ${ }^{1}$, Aurora Wang ${ }^{1}$, Ingrid Santana $^{1}$ \\ ${ }^{1}$ Departamento de Ciência da Computação - Universidade de Brasília (UnB) \\ Campus Darcy Ribeiro - CEP 70910-900 - Brasília - DF - Brasil \\ carlacastanho@unb.br, auroralimin14@gmail.com, ingrid95sl@gmail.com
}

\begin{abstract}
In recent years, it has been observed that electronic games are no longer primarily male interest. However, the female presence in the videogame industry is still small. This work shares the results of a survey conducted with women who have some relationship with electronic games, whose objective is to identify the current scenario regarding the presence of women in the area of electronic game development in Brazil, with emphasis in the area of Programming of games.
\end{abstract}

Resumo. Nos últimos anos, têm-se observado que os jogos eletrônicos deixaram de ser um interesse essencialmente masculino. Contudo, presença feminina na indústria destes artefatos de software ainda é pequena. Este trabalho compartilha os resultados de uma pesquisa realizada com mulheres que possuem alguma relação com jogos eletrônicos, cujo objetivo é identificar o cenário atual no que diz respeito à presença das mulheres na área de desenvolvimento de jogos eletrônicos no Brasil, com ênfase na área de Programação de Jogos.

\section{Introdução}

Recentemente, tem-se observado um crescimento global de mulheres que declaram jogar algum tipo de jogo eletrônico. Em vários países a porcentagem do público feminino consumidor de jogos tem se equiparado ao masculino [MediaCT 2012], [ISFE 2016], [Statistica 2018]. No Brasil, considerado um país com alto consumo desse tipo de produto, o público feminino foi de 53,6\% em 2017 [Pesquisa Game Brasil 2017].

No entanto, dados mostram que as mulheres correspondem a uma pequena parcela da força de trabalho na indústria de Jogos Digitais. No Brasil, no ano de 2014, as mulheres representavam apenas $15 \%$ dos profissionais atuando em diversas áreas deste ramo, como game design, animação, programação, dentre outras [Fleury 2014]. O cenário é ainda mais desfavorável no que diz respeito às mulheres que trabalham com TI com foco em jogos. No âmbito mundial, elas representam somente $23 \%$ no total de profissionais [Weststar 2018].

Partindo-se da premissa que o interesse em atuar com desenvolvimento de jogos é também motivado pelas suas próprias experiências como consumidor e que foi reconhecida a necessidade de diversidade de gênero no meio [Weststar 2018], esse trabalho tem como objetivo apresentar um panorama do cenário atual das mulheres na área de desenvolvimento de jogos eletrônicos no Brasil, com ênfase na área de Programação de Jogos. 


\section{Metodologia}

Para a coleta dos dados deste estudo foi elaborado um questionário cujo público alvo são mulheres com algum envolvimento com Jogos Eletrônicos. O instrumento é composto por três partes: (1) Dados pessoais, (2) Relação com a área de jogos, e (3) Contato com a área de desenvolvimento de jogos digitais. Visando anonimato, os únicos dados pessoais coletados foram idade e escolaridade. A Parte 2 concentrou-se em identificar (i) há quanto tempo a participante tem contato com jogos eletrônicos, (ii) se o fato de ser mulher afetou o seu acesso aos jogos eletrônicos e por fim (iii) classificar o perfil entre: (a) Somente Jogadora; (b) Atuante em desenvolvimento de jogos com foco em Outras Áreas que não a Programação; (c) Atuante em desenvolvimento de jogos com foco em Programação.

Após a identificação do perfil, a Parte 3 do questionário foi elaborada com perguntas específicas para cada perfil, sendo que um perfil não teve acesso às perguntas para os demais perfis. Acredita-se que as respondentes que possuem o perfil "Somente Jogadora" podem contribuir para o levantamento, pois não é incomum encontrar programadoras que tiveram seu interesse despertado pela área por terem sido jogadoras na sua sua infância ou adolescência. Da mesma forma, as respondentes que atuam em outras áreas de jogos que não a programação, frequentemente estão inseridas em equipes de trabalho que incluem programadores. Assim, sua interação neste meio pode fornecer uma perspectiva do cenário em seus ambientes de trabalho e/ou estudo.

O questionário foi amplamente divulgado em grupos da rede social Facebook relacionados a jogos eletrônicos, além de listas de email do meio acadêmico, científico e profissional da área de desenvolvimento de jogos eletrônicos no Brasil. A URL com questionário ficou disponível para preenchimento por um período de três semanas durante o mês de março de 2018.

\section{Resultados}

O questionário foi respondido por 151 mulheres, cuja maioria de $88 \%$ possui idade entre 17 e 31 anos. A faixa etária média foi de 26 anos, sendo que a mais jovem tem 15 anos e a mais velha 63 anos. Assim, a pesquisa conseguiu reunir dados, em sua maioria, daquelas que já terminaram o ensino básico e/ou ingressaram no mercado de trabalho. Nota-se que as respondentes têm contato com jogos digitais, em média, há 15,6 anos. Assim, concluiu-se que este contato deu-se para muitas ainda durante a infância.

Quando questionadas se acreditam que o gênero limitou o seu acesso aos jogos eletrônicos, foi fornecida uma escala de 1 a 10, onde 1 significa "Discordo Totalmente" e 10 "Concordo Totalmente". Um pouco mais da metade $(54,3 \%)$ marcaram entre 6 a 10, ou seja, consideram que de alguma forma houve limitação por causa do seu gênero; enquanto enquanto $45,7 \%$ marcaram entre 1 e 5 e portanto discordam de algum modo desta afirmação. As principais justificativas apresentadas pela respondentes que concordam com o fato do seu gênero ter limitado ou influenciado seu acesso aos jogos eletrônicos, estão relacionadas a questões de sexualização da mulher nos jogos, subestimação da mulher quanto a capacidade de jogar, privação de acesso a determinados jogos, considerados violentos, ou a qualquer tipo de jogo eletrônico, por serem considerados "coisa de menino". Tais resultados corroboram com os apresentados e discutidos em [Fragoso 2017], principalmente os dois primeiros. Por outro lado, as participantes que acreditam que o gênero não influenciou o seu acesso aos 
jogos eletrônicos, justificam que seu acesso foi facilitado por terem tido, em sua infância ou adolescência, irmãos ou pais que jogavam videogame em casa.

Com relação ao perfil das participantes da pesquisa, 66,9\% se declararam como somente jogadoras, $27,8 \%$ atuam em outras áreas que não a de programação e apenas $5,3 \%$ atuam como programadoras (Figura 1). Percebe-se uma diferença significativa entre o número de mulheres atuantes em programação e aquelas que atuam em outras áreas de desenvolvimento de jogos. Relacionando estes dados, conclui-se que dentre as respondentes que trabalham com jogos digitais, apenas 16\% são programadoras.

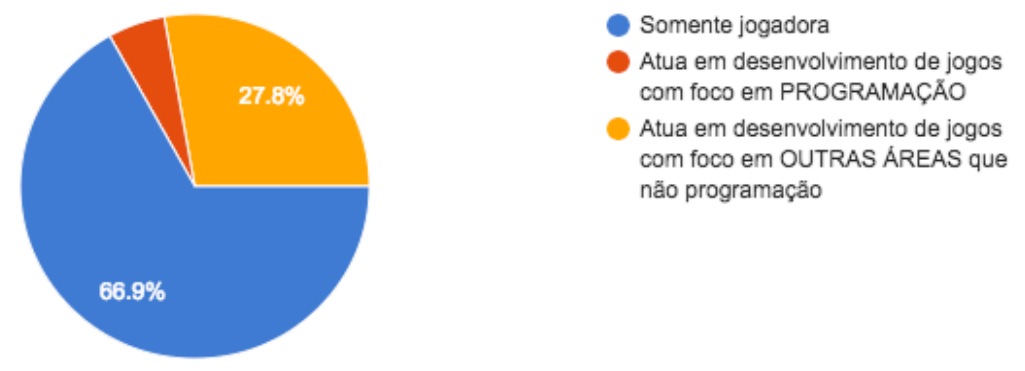

Figura 1. Perfil das respondentes

Dentre as respondentes que relatam possuir relação com jogos eletrônicos apenas como Jogadoras, 70,3\% têm curiosidade quanto ao desenvolvimento de jogos digitais e 69,3\% já consideraram atuar na área. No entanto, ao indagadas se acreditam que o fato serem mulheres atrapalharia uma carreira na área, $28,4 \%$ responderam que "sim" e 39,6\% acreditam que "talvez sim". Dentre as principais justificativas apresentadas destacam-se: (i) ambiente predominantemente masculino, (ii) subestimação das mulheres no trabalho, (iii) questionamento de gostos e capacidades, além de (iv) assédio e (v) machismo. O trabalho de [Fragoso 2017] aponta exemplos similares, tais como tratamento diferenciado por serem mulheres e a incredulidade dos homens quanto as habilidades das mulheres para jogar videogames.

Apesar de 61,4\% das respondentes afirmarem que já consideraram atuar como programadora, um percentual ligeiramente menor, de $58,4 \%$, disse ter noção das tarefas que uma programadora desempenha. 45,6\% das respondentes do perfil "Somente Jogadora" acredita que o fato de ser mulher poderia atrapalhar uma possível atuação como programadora. As justificativas apresentadas residem em questões relacionadas à machismo, preconceito e falta de crédito pelo trabalho desempenhado.

Do total de 151 respondentes do questionário deste estudo, 27,8\% correspondem às que atuam em outras áreas do desenvolvimento de jogos que não a programação, tais como: Game Design (64,3\%), Ilustração (47,6\%), Gestão $(33,33 \%)$, Teste $(33,3 \%)$, Animação (31\%) e Música (9,5\%), etc. Contudo, 59,5\% destas profissionais afirmam ter interesse em desenvolver habilidades de programação de jogos.

No que diz respeito a presença de mulheres programadoras nas equipes de desenvolvimento de jogos com as quais trabalharam, 38,1\% afirmaram que raramente as equipes são compostas por mulheres, $23,8 \%$ declararam nunca terem trabalhado com programadoras mulheres e $21,4 \%$ alegaram que as mulheres eram minoria nas equipes (Figura 2). Apenas uma participante apontou ter trabalhado com equipes onde a quantidade de programadores homens e mulheres era aproximadamente a mesma. Da 
mesma forma, somente uma participante relatou ter participado de uma equipe onde a maioria das programadoras eram mulheres.
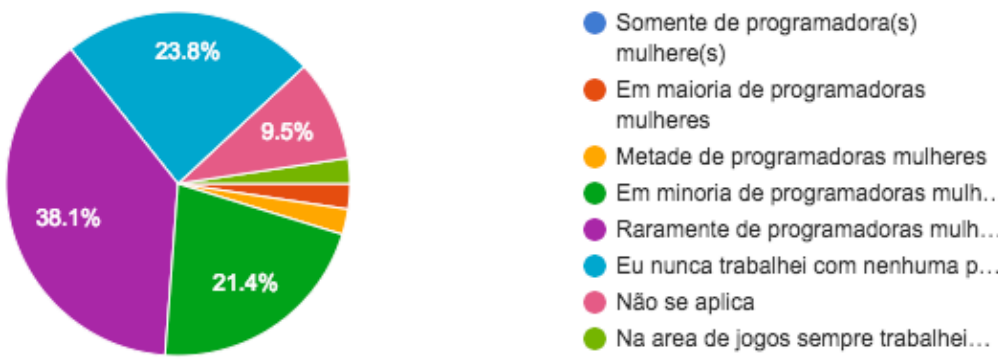

Figura 2. Formação das equipes de programação em jogos eletrônicos

Apesar do questionário ter sido divulgado em diversos ambientes de estudo, ensino, pesquisa e criação de jogos digitais, apenas 5,3\% das 151 respondentes são programadoras de jogos eletrônicos, o que corresponde somente a 8 mulheres. Quando questionadas se acreditam que são tratadas de forma diferente dos programadores do sexo masculino, 5 (cinco) confirmaram que "sim". Algumas justificativas apresentadas foram: (i) necessidade de provar sua competência, e, (ii) sem perguntar, as pessoas presumem que por ser mulher a profissional é artista ou designer. Além disso, 3 (três) respondentes afirmam já terem passado por alguma situação desconfortável no âmbito profissional, como assédio pelo chefe, por exemplo.

\section{Considerações Finais}

Apesar das mulheres representarem hoje uma grande parcela do público consumidor de jogos eletrônicos, este trabalho constatou que muitas delas acreditam que o seu gênero limitou de alguma forma seu acesso a esses jogos. Além disso, o sentimento de ter seu potencial limitado nesta área de trabalho foi relatado por todas as mulheres que atuam em desenvolvimento de jogos, tanto programadoras, como as demais. Assim, ainda existem barreiras a serem superadas no que diz respeito a receptividade da comunidade de jogos em relação às mulheres. Isso ficou explícito nesta pesquisa, ao encontrarmos tão poucas participantes programadoras de jogos, bem como um baixo número de mulheres que compõe as equipes de programação de jogos.

Espera-se que o presente trabalho sirva de incentivo a iniciativas que visem desmistificar o fato de que a área de desenvolvimento de jogos, mais precisamente, de programação de jogos, é um ramo essencialmente masculino. Muitas pessoas ainda enxergam o trabalho de arte em jogos, por exemplo, como uma atividade mais feminina e o trabalho de programação como mais masculino. Ações no sentido de desvincular o tipo de atividade, seja ela de arte ou programação, por exemplo, do gênero ainda são poucas ou praticamente inexistentes na área de jogos eletrônicos.

Como trabalhos futuros, pretende-se ampliar a abrangência desta pesquisa a nível internacional a fim de levantar se o cenário identificado no Brasil é particular ou se representa também a situação mundial para o nicho em questão. Outra possibilidade é investigar no âmbito universitário, qual o interesse das estudantes em seguir a carreira na área de desenvolvimento de jogos, mais precisamente na área de programação. Destaca-se que o presente trabalho não se concentrou em uma determinada faixa etária ou escolaridade. 


\section{Referências}

Weststar, J., O’Meara, V.,Legault, M. J. (2018). Developer Satisfaction Survey 2017 Summary Report.

Statistica. (2018). Distribution of computer and video gamers in the United States from 2006 to 2017, by gender. https://www.statista.com/statistics/232383/gender-split-of-uscomputer-and-video-gamers/.

Pesquisa Game Brasil. (2017). Comportamento, consumo e tendências do gamer brasileiro.

Fleury, A., Sakuda, L. O., \& Cordeiro, J. H. D. O. (2014). I censo da indústria brasileira de jogos digitais. NPGT-USP e BNDES: São Paulo e Rio de Janeiro.

Fragoso, S., Recuero, R., \& Caetano, M. (2017). Violência de gênero entre gamers brasileiros: um estudo exploratório no Facebook. Lumina, 11(1).

MediaCT, I. (2012). Videogames in Europe: Consumer study. European summary report.

ISFE GameTrack(2016). GameTrack Digest: Quarter 1. 